\title{
Arctic sea-ice change tied to its mean state through thermodynamic processes
}

Authors: François Massonnet ${ }^{* a, b}$, Martin Vancoppenolle $^{c}$, Hugues Goosse ${ }^{\mathrm{a}}$, David Docquier ${ }^{\mathrm{a}}$, Thierry Fichefet ${ }^{\mathrm{a}}$, Edward Blanchard-Wrigglesworth $^{\mathrm{d}}$

\section{Affiliations:}

${ }^{\mathrm{a}}$ Georges Lemaître Centre for Earth and Climate Research (TECLIM), Earth and Life Institute (ELI), Université catholique de Louvain (UCL), Louvain-la-Neuve, Belgium

${ }^{\mathrm{b}}$ Earth Sciences Department, Barcelona Supercomputing Center, Barcelona, Spain

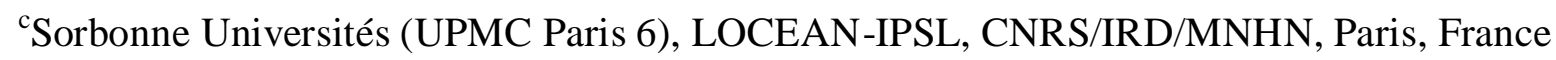

${ }^{\mathrm{d}}$ Department of Atmospheric Sciences, University of Washington, Seattle, Washington, USA

*Corresponding author (francois.massonnet@uclouvain.be) 


\section{SUMMARY PARAGRAPH / ABSTRACT}

One of the clearest manifestations of ongoing global climate change is the dramatic retreat and thinning of the Arctic sea-ice cover ${ }^{1}$. While all state-of-the-art climate models consistently reproduce the sign of these changes, they largely disagree on their magnitude ${ }^{1-4}$, the reasons for which remain contentious ${ }^{3,5-7}$. As such, consensual methods to reduce uncertainty in projections are lacking ${ }^{7}$. Here, using the CMIP5 ensemble, we propose a process-oriented approach to revisit this issue. We show that inter-model differences in sea-ice loss and, more generally, in simulated sea-ice variability, can be traced to differences in the simulation of seasonal growth and melt. The way these processes are simulated is relatively independent of the complexity of the sea-ice model used, but rather a strong function of the background thickness. The larger role played by thermodynamic processes as sea ice thins ${ }^{8,9}$ further suggests the recent ${ }^{10}$ and projected $^{11}$ reductions in sea-ice thickness induce a transition of the Arctic towards a state with enhanced volume seasonality but reduced interannual volume variability and persistence, before summer ice-free conditions eventually occur. These results prompt modelling groups to focus their priorities on the reduction of sea-ice thickness biases. 


\section{MAIN TEXT}

Sea ice is a major element of the Arctic environment. It largely shapes the climate and dynamics of ecosystems, the life of indigenous populations and the rhythm of socioeconomical activities in the High North. Nearly four decades of remote-sensing observations have revealed that Arctic sea ice is changing at a rapid pace. Some of the most spectacular indicators are the significant negative trends in area and thickness identified in all seasons ${ }^{1}$. Numerical General Circulation Models (GCMs) have routinely been used for decades to investigate the underlying mechanisms of sea-ice loss. For example, GCMs have been instrumental in formally attributing sea-ice decline to human-induced activities ${ }^{1}$. Substantial uncertainty persists, however, on the rate of sea-ice loss projected by these models ${ }^{1-7}$ at strategic time scales for infrastructure upgrade and adaptation (i.e., from a season to $\sim 30$ years). Research has indicated that, at these time scales, model error and internally generated climate variability are the dominant factors contributing to uncertainty ${ }^{11,12}$.

A prominent feature of the Arctic sea-ice cover is its pronounced seasonality (Fig. 1a). Interestingly, sea-ice extent trend and variability are enhanced in summer over winter. This seasonal asymmetry in trend and, to a larger extent, in year-to-year variability (Fig. 1a) may appear surprising given that lower troposphere air temperatures in the Arctic have increased at least four times as much in winter as in summer ${ }^{13}$. In fact, sea-ice extent variability is not only controlled by the atmospheric forcing, but also amplified or damped by internal feedbacks. The natural processes of seasonal growth and melt of sea ice are modulated by two types of opposing thermodynamic feedbacks that operate during distinct seasons. A negative anomaly of sea-ice area in late summer induces larger heat losses in fall and winter from ocean to atmosphere due to enhanced outgoing long-wave radiation and turbulent heat fluxes ${ }^{14}$. This causes thinner snow and ice due to later freeze-up and hence larger heat-conduction fluxes through sea ice (assuming surface temperature is unchanged), eventually leading to larger icegrowth rates. This implies a negative (stabilising) feedback, commonly referred to as the 'ice thickness-ice growth feedback ${ }^{\prime 15}$. In spring, an initial decrease in surface albedo (due to early sea-ice retreat, thinning, formation of melt ponds, or early snow loss) facilitates shortwave radiation absorption by the ice and ocean, and causes air and ocean surface temperatures to rise. This enhances ice-surface and -bottom melt, and leads to a further reduction in albedo. This implies a positive (amplifying) feedback, commonly referred to as the 'ice-albedo feedback ${ }^{15,16}$.

A state-of-the-art $\mathrm{GCM}^{17}$ well tested in the $\operatorname{Arctic}^{18}$ offers a longer-term and more complete perspective than observations, on the role played by the two opposing feedbacks in the changing Arctic (Fig. 1b-e). As the ice thins, open-water formation increases during the melting season over most of the Arctic basin (positive feedback, Fig 1b-c), but an increase in wintertime sea-ice production occurs during the next ice-growth season (negative feedback, Fig. 1 d-e) despite larger winter air temperatures.

However, characterising such feedbacks is not straightforward, as this generally requires dedicated numerical experiments in which the feedback studied is excluded and the model response to a perturbation is compared to the response with the feedback included. Such 
targeted simulations are usually not available for large multi-model ensembles such as the Coupled Model Intercomparison Project, phase 5 (CMIP5, see Methods). Therefore, a comprehensive assessment of the two aforementioned feedbacks cannot be undertaken in CMIP5. Instead, we here estimate the efficiency at which the two underlying processes of seaice growth and melt operate in CMIP5 models. For this purpose, we introduce two diagnostics aimed at investigating the thermodynamics of sea ice in climate models. Following an earlier study $^{8}$, we introduce the 'open-water-formation efficiency' (OWFE), a diagnostic quantifying the area of open water formed in a control region for a unit reduction in sea-ice volume. We also introduce the dual diagnostic, the 'ice-formation efficiency' (IFE), as the wintertime volume gain per unit of previous summer volume change. Both diagnostics are evaluated north of $80^{\circ} \mathrm{N}$ and come as one number for a given time window (see Methods).

The OWFE and IFE, diagnosed in the central Arctic and on the basis of seasonal relationships, are found to have a direct connection to the longer term basin-wide sea-ice area and volume variability in the CMIP5 ensemble (Table 1). In particular, the IFE (OWFE) tightly controls wintertime (summertime) ice-volume (-area) trends (Table 1). Models that melt sea-ice area more efficiently (i.e., those with large OWFEs) also display more negative trends in summer sea-ice area, likely because the same physical processes are at play on both time scales. These relationships also hold when OWFE/IFE and the sea-ice variability indices are considered over distinct periods. By making the connection between variability on short and long time scales but also between regional and basin-wide spatial scales, the OWFE and IFE therefore offer prospects to identify physical drivers behind simulated Arctic sea-ice seasonality, interannual variability, persistence and trends in GCMs. These relationships can formally be reckoned as 'emergent constraints', i.e. collective behaviours emerging from a model ensemble between current and future climate characteristics ${ }^{19}$. Therefore, to understand the origins of spread in future sea-ice properties simulated by the CMIP5 models, it is necessary to first identify the fundamental drivers behind the OWFE and IFE themselves.

A clear inverse relationship is identified between the efficiency of the two thermodynamic processes (IFE and OWFE) and the annual mean sea-ice volume north of $80^{\circ} \mathrm{N}$ (the 'mean state' hereinafter) in the CMIP5 ensemble (Fig. 2a,c; $n=146$ runs from 44 GCMs). The thickness-dependence of vertical sea-ice thermodynamics is a basic feature of sea-ice physics and the enhancement of processes as ice thins has already been documented in earlier studies ${ }^{8,9}$. However, it is unclear whether the mean state is the dominant parameter affecting the strength of the thermodynamic processes in the real world and in GCMs. The level of sophistication of sea-ice physics in the models could be another important factor. It could be expected, for instance, that models with a subgrid-scale ice-thickness distribution would resolve growth and melt processes more accurately, and therefore simulate IFE and OWFE differently from models with simpler physics. To test this hypothesis, we grouped the 44 GCMs into four categories according to their sea-ice component (very simple, simple, intermediate and complex) and found no obvious link between model physics on the one hand, and OWFE, IFE and the mean state on the other hand (Extended Data Fig. 1; Methods). Experiments conducted with a toy 1-D sea-ice ocean-mixed-layer model reproduce the CMIP5 behaviour (Fig. 2 b,d) and suggest that OWFE and IFE obey this fundamental 
dependence to thickness regardless of model complexity. In addition, sensitivity experiments conducted with that toy model indicate that the mean state is the primary factor affecting the process strength, however that mean state may have been achieved. The fraction of variance in IFE and OWFE unexplained by the mean state (Fig. 2a-c) can be attributed to internal variability, that is, variability generated in the coupled climate system itself due to the numerous nonlinearities and feedbacks therein. Indeed, analyses using a large $(n=35)$ ensemble of historical integrations from the Community Earth System Model (CESM-LE) ${ }^{17}$ show that the spread in IFE and OWFE simulated within the same model for a given period is indeed comparable with the inter-model spread simulated by CMIP5 (Methods).

The striking similarities between the CMIP5 models and a toy model (Fig. 2), on the one hand, and the lack of obvious link between model complexity and process strength (Extended Data Fig. 1), on the other hand, all underline that the first-order thermodynamic behaviour of sea ice in GCMs is remarkably consistent and simple at the temporal and spatial scales considered here. In particular, the level of sophistication of a sea-ice model appears relatively unimportant in shaping the sea-ice mean state of that model with regard to other influences. It must be noticed, however, that model diversity is relatively poor in the CMIP5 ensemble: the sea-ice components share very similar dynamic cores, while the main thermodynamic differences stand from the ice thickness distribution scheme. In any case, understanding how atmospheric or oceanic biases affect the sea-ice state as well as a more diligent documentation on tuning methods ${ }^{7,20}$ are likely to give clear insights about the source of spread in current sea-ice projections. This will hopefully be the case for the upcoming round of inter-model comparison, CMIP6, for which the ad-hoc diagnostics will be available ${ }^{21}$.

Our multi-model analysis predicts that growth and melt processes are enhanced nonlinearly for models with thin ice (Fig. 2) and that this enhancement affects simulated Arctic sea-ice volume variability at longer time scales (Table 1). We can therefore expect that, in a model with declining mean state, sea-ice volume variability is affected through the enhanced action of growth and melt processes. Analyses conducted with the CESM-LE reveal that this dependence indeed occurs in this model (Fig. 3). According to this GCM and a sea-ice reanalysis ${ }^{22}$, Arctic sea-ice volume has already experienced its most negative trends and largest year-to-year variability. As the ice thins further, sea-ice volume will become less persistent and exhibit less variability from one year to another. This contrasts with the projected increases in summer sea-ice area variability and predictability, both regionally and Arctic-wide ${ }^{23,24}$.

The existence of relationships between the mean state and the efficiency of thermodynamic processes, on the one hand, and between this efficiency and sea-ice area and volume variability, on the other hand, allows to physically reinterpret the tight link that had been noticed in earlier studies between mean state, seasonality, persistence, variability and trends $s^{9,24,25}$ and seen in this study (Fig. 3). It also has an important implication: the confidence in near-term predictions or long-term projections from models with a biased mean state should be questioned. Indeed, linear post-processing methods widely used in the literature ${ }^{11,26}$ appear no longer justified since growth and melt efficiency, and hence sea-ice area and volume variability, changes with the mean state. For the same reasons, weighted linear 
combination of model outputs ${ }^{27}$ have certainly statistical value but little physical basis. Based on our findings, sea-ice projections obtained from simulations that have Arctic sea-ice volume outside the observational range should be discarded as those simulations will not simulate future thermodynamic sea-ice thinning correctly. Importantly, this does not mean that GCMs with correct mean states are necessarily trustful for the future. Indeed, a failure to simulate other, non-thermodynamic processes (e.g., sea-ice dynamics) may imply unreliable projected sea-ice loss too. In addition, the current spatial distribution of sea-ice thickness ${ }^{28}$ or the sensitivity of sea-ice extent to near-surface air temperatures ${ }^{29}$ are known critical factors driving the future evolution of the sea-ice cover.

Given the importance of the mean state for ice-volume trends as highlighted in this study, a natural final step would be to apply an observational constraint on the simulated volume projections. However, estimating reliably the annual mean sea-ice volume directly from observations is challenging, due to the short period for which large-scale estimates of sea-ice thickness are available ( 15 years). In addition, sea-ice thickness estimates are highly uncertain not only because of instrumental errors, but also because of the numerous assumptions on geophysical parameters (snow load, seawater, sea-ice and snow densities) used to retrieve the actual thickness from the raw measurements ${ }^{30}$. Following a highly conservative methodology that takes these observational uncertainties into account (see Methods), we come to the conclusion that it is currently not possible to significantly reduce the spread in projected Arctic sea-ice volume loss (Fig. 4) due to too uncertain observations. Reducing uncertainties in sea-ice area trend with the same constraint on sea-ice volume appears to be even more challenging, as future trends in sea-ice area are subject to high internal variability ${ }^{7}$. Thus, in line with the analyses presented in this study, the current main obstacle to reducing uncertainties in projected sea-ice volume or area trends is not the complexity of the models used, but rather the lack of long-term and reliable estimates of seaice volume that can be used to constrain their projections. 


\section{MAIN REFERENCES}

1. IPCC, Climate Change 2013: The Physical Science Basis, Contribution of Working Group I to the Fifth Assessment Report of the Intergovernmental Panel on Climate Change, Cambridge Univ. Press, Cambridge (2013)

2. Stroeve, J., Kattsov, V., Barrett, A. P., Serreze, M., Pavlova, T., Holland, M., \& Meier, W.Trends in Arctic sea ice extent from CMIP5, CMIP3 and observations. Geophys. Res. Lett.39, L16502 (2012)

3. Massonnet, F., Fichefet, T., Goosse, H., Bitz, C. M., Philippon-Berthier, G., Holland, M. M., \& Barriat, P. Y. Constraining projections of summer Arctic sea ice. Cryosphere, 6, 1383-1394 (2012)

4. Wang, M., \& Overland, J. E. A sea ice free summer Arctic within 30 years: An update from CMIP5 models. Geophys. Res. Lett. 39, L1850 (2012)

5. Rosenblum, E., \& Eisenman, I. Sea ice trends in climate models only accurate in runs with biased global warming. J. Climate. 30, 6265-6278 (2017)

6. Mahlstein, I., \& Knutti, R. Ocean heat transport as a cause for model uncertainty in projected arctic warming. J. Climate, 24 1451-1460 (2011)

7. Notz, D. How well must climate models agree with observations? Phil. Trans. Roy. Soc. A 373, 2052 (2014)

8. Holland, M. M., Bitz, C. M. \& Tremblay, B. Future abrupt reductions in the summer Arctic sea ice. Geophys. Res. Lett. 33, L23503 (2006)

9. Bitz, C. M. \& Roe, G. H. A mechanism for the high rate of sea ice thinning in the Arctic Ocean. J. Clim. 17, 3623-3632 (2004)

10. Kwok, R. et al. Thinning and volume loss of the Arctic Ocean sea ice cover: 20032008. J. Geophys. Res. 114, C07005 (2009)

11. Melia, N., Haines, K. \& Hawkins, E. Improved Arctic sea ice thickness projections using bias-corrected CMIP5 simulations. Cryosphere 9, 2237-2251 (2015)

12. Swart, N., Fyfe, J. C., Hawkins, E., Kay, J. E. \& Jahn, A. Influence of internal variability on Arctic sea-ice trends. Nature Clim. Change 5, 86-89 (2015)

13. Bintanja, R. \& van der Linden, E. C. The changing seasonal climate in the Arctic. Sci. Rep. 3, 1556 (2013)

14. Holland, M. M., Serreze, M. C. \& Stroeve, J. The sea ice mass budget of the Arctic and its future change as simulated by coupled climate models. Clim. Dyn. 34, 185 (2010) 
15. Notz, D. and Bitz, C. M. Sea ice in Earth system models. in Sea Ice (Thomas Ed), John Wiley \& Sons (2017)

16. Curry, J. A., Schramm, J. L. and Ebert, E. E. Sea Ice-Albedo Climate Feedback Mechanism. J. Climate 8 240-247 (1995)

17. Kay, J.E., et al. The Community Earth System Model (CESM) Large Ensemble Project: A Community Resource for Studying Climate Change in the Presence of Internal Climate Variability. Bull. Amer. Meteor. Soc. 96, 1333-1349 (2015)

18. Barnhart, K. R., Miller, C. R., Overeem, I., \& Kay, J. E. Mapping the future expansion of Arctic open water. Nature Clim. Change 6, 280-285 (2016)

19. Wenzel, S., Cox, P. M., Eyring, V. and Friedlingstein, P. Projected land photosynthesis constrained by changes in the seasonal cycle of atmospheric CO2. Nature 538 499-501 (2016)

20. Hunke, E. Thickness sensitivities in the CICE sea ice model. Ocean Model. 34, 137149 (2010)

21. Notz, D. et al. Sea Ice Model Intercomparison Project (SIMIP): Understanding sea ice through climate-model simulations. Geosci. Model Dev. 9 3427-3446 (2016)

22. Schweiger, A., Lindsay, R., Zhang, J., Steele, M., Stern, H. Uncertainty in modeled Arctic sea ice volume. J. Geophys. Res.116, C00D06 (2011)

23. Cheng, W., E. Blanchard-Wrigglesworth, C. M. Bitz, C. Ladd, and P. J. Stabeno (2016), Diagnostic sea ice predictability in the pan-Arctic and U.S. Arctic regional seas. Geophys. Res. Lett. 43, 11,688-11,696 (2016)

24. Goosse, H., Arzel, O., Bitz, C. M., de Montety, A. and Vancoppenolle, M. Increased variability of the Arctic summer ice extent in a warmer climate. Geophys. Res. Lett. 36, L23702 (2009)

25. Blanchard-Wrigglesworth, E. \& Bitz, C. M. Characteristics of Arctic sea-ice variability in GCMs. J. Clim. 27, 8244-8258 (2014)

26. Fučkar, N. S., Volpi, D., Guemas, V. \& Doblas-Reyes, F. J. A posteriori adjustment of near-term climate predictions: Accounting for the drift dependence on the initial conditions, Geophys. Res. Lett. 41, 5200-5207 (2014)

27. Knutti, R. et al. A climate model projection weighting scheme accounting for performance and interdependence. Geophys. Res. Lett 44, 1909-1918 (2017)

28. Stroeve, J., Barrett, A., Serreze, M., and Schweiger, A. Using records from submarine, aircraft and satellites to evaluate climate model simulations of Arctic sea ice thickness. Cryosphere 8, 1839-1854 (2014) 
29. Zhang, X. Sensitivity of Arctic Summer Sea Ice Coverage to Global Warming Forcing: Toward Reducing Uncertainty in Arctic Climate Change Projections. Tellus A 62, 220-227 (2010)

30. Zygmuntowksa, M., Rampal, P., Ivanova, N., \& Smedsrud, L. H. Uncertainties in Arctic sea ice thickness and volume : new estimates and implications for trends. Cryosphere 8 705-720 (2014)

31. Fetterer, F., K. Knowles, Meier, W., Savoie, M. \& Windnagel, A. K., updated daily. Sea Ice Index, Version 2. [G02135]. Boulder, Colorado USA. NSIDC: National Snow and Ice Data Center. doi: http://dx.doi.org/10.7265/N5736NV7 (2017)

32. van Vuuren, D. et al. The representative concentration pathways: an overview. Clim. Change 109 5-31 (2011)

33. EUMETSAT Ocean and Sea Ice Satelitte Application Facility. Global sea ice concentration reprocessing dataset 1978-2015 (v1.2, 2015), [Online]. Norwegian and Danish Meteorological Institutes. Available from http://osisaf.met.no

\section{Correspondence}

Correspondence and requests for materials should be addressed to François Massonnet (francois.massonnet@uclouvain.be).

\section{Acknowledgments}

The research leading to these results has received funding from the Belgian Fonds National de la Recherche Scientifique (F.R.S.-FNRS), the European Commission's Horizon 2020 projects APPLICATE (GA 727862) and PRIMAVERA (GA 641727). We acknowledge the World Climate Research Programme's Working Group on Coupled Modelling, which is responsible for CMIP, and we thank the climate modelling groups (listed in the supplement) for producing and making available their model output. We acknowledge the CESM Large Ensemble Community Project and supercomputing resources provided by NSF/CISL/Yellowstone for access to the CESM-LE data. The authors thank C. M. Bitz and D. Notz for useful discussions, and F. Kauker for providing the ITRP data. The authors thank M. M. Holland, E. C. Hunke and one anonymous reviewer for the review of this manuscript.

\section{Author contributions}

F.M., M.V. and H.G. designed the science plan. All authors contributed to the design of the study. F.M. assembled the data and wrote the manuscript. 
Table 1 | Linear correlation statistics between indices of sea-ice variability (whole Arctic domain) and the simulated processes of growth and melt, namely IFE and OWFE evaluated in the domain $>80^{\circ} \mathrm{N}$ ( $n=44$ CMIP5 models, 1955-2004). A graphical view of these relationships is available in Extended Data Fig. 2.

Correlation coefficient ( $p$-value, one-sided)

IFE OWFE

\begin{tabular}{ccc}
\hline $\begin{array}{c}\text { Amplitude of ice-volume } \\
\text { seasonal cycle }\end{array}$ & $-0.53(0.0001)$ & $0.52(0.0001)$ \\
\hline Standard deviation of .. & $\ldots$ March sea-ice volume & $\ldots$ September sea-ice area \\
\hline $\begin{array}{c}\text { Persistence, defined as } e \text {-folding } \\
\text { time scale of linearly detrended } \\
\text { ice-volume anomalies }\end{array}$ & $0.59(0.0001)$ & $0.66\left(<10^{-6}\right)$ \\
\hline Linear change in... & $\ldots$ March sea-ice volume & $\ldots .0 .29(0.03)$ \\
\hline & $-0.33(0.015)$ & $-0.45(0.001)$ \\
\hline
\end{tabular}


Figure 1 | Changing seasonality of Arctic sea-ice cover. a, Seasonal cycle of daily sea-ice extent retrieved from satellite monitoring ${ }^{31}$, coloured by year (1979-2017). The bottom grey series indicates the range (max-min) of sea-ice extent for each day of the year, after linear detrending of the data to remove a first-order estimate of secular trends. b-c Average open-water seasonal formation for past (1850-1880) and future (2020-2050) conditions estimated from the CESM-LE ${ }^{17}$ forced under historical and then Representative Concentration Pathway ${ }^{32}$ (RCP) 8.5 forcings. Open-water seasonal formation is defined for each calendar year, and each grid cell, as the range ( $\max -\mathrm{min})$ in sea-ice concentration for that year and that grid cell. d-e Average sea-ice thickness seasonal change for the same past and future periods as in b-c, using the same model outputs. Sea-ice thickness seasonal change is defined for each calendar year and each grid cell as the range (max-min) of sea-ice thickness between July $1^{\text {st }}$ and June 30st of the next year. Light-pink contour lines denote the 15\% contour line of September sea-ice concentration averaged over the two reference periods. 
Figure 2 | Efficiency of growth and melt processes as a function of the mean state. a, Iceformation efficiency (IFE, see Methods) estimated from 44 CMIP5 models and their members $(n=146)$ over 1955-2004, plotted against the mean state defined as the annual mean sea-ice volume north of $80^{\circ} \mathrm{N}$ averaged over the same period. Individual model realisations are plotted as dots and ensemble means as circles; the size of circles is proportional to the number of members used for averaging. A full referencing of CMIP5 models is available in Extended Data Table 1. Also plotted are estimates from a sea-ice reanalysis ${ }^{22}$ (1979-2015) and from satellite retrievals ${ }^{10,33}$ (2003-2008). Error bars on both estimates are the standard deviation on the corresponding diagnostics and mean state (see Methods). b, IFE against mean state estimated from a 1-D sea-ice-ocean-mixed-layer model (see Methods) integrated under reference conditions (black dot) and with varying sea-ice conductivity, albedo and forcing (blue, green and red dots, respectively). The grey envelopes are the one and two standard deviation confidence intervals from a $1 / x$ fit of the CMIP5 data presented in a. c, same as a but for the open-water-formation efficiency (OWFE). d, same as b but for the OWFE. 
Figure 3 | Influence of mean state on sea-ice volume variability. Relationship between four indices of total Arctic sea-ice-volume variability ( $y$-axes) and the mean state (annual mean Arctic sea-ice volume north of $\left.80^{\circ} \mathrm{N}\right)\left(x\right.$-axes) in a 35 -member model ensemble $\left(C E S M-L^{17}\right)$ integrated under historical and then RCP8.5 forcings ${ }^{32}$. The analysis is conducted on sliding 20-yr windows (colour shading). a, Mean amplitude of the seasonal cycle; $\mathbf{b}$, standard deviation of annual mean sea-ice volume; c, persistence, estimated as the $e$-folding time scale of linearly detrended anomalies of sea-ice volume; $\mathbf{d}$, linear trend in annual mean sea-ice volume. Black crosses and error bars (see Methods) correspond to the estimated mean state and variability from a sea-ice reanalysis ${ }^{22}$. 
Figure 4 | Challenges in reducing uncertainties of sea-ice volume projections. Time series of annual mean Arctic sea-ice volume from historical and RCP8.5 forcings ${ }^{32}$ (72 simulations available). Colours are referenced in Extended Table 1. Grey time series correspond to simulations with sea-ice volume north of $80^{\circ} \mathrm{N}$ deemed incompatible with three observational references (see Methods). The statistics reported at the top of the figure refer to the ensemble mean and standard deviation of annual mean sea-ice volume linear change over 2020-2050 (for the full set of models, "ALL"; and for the subset, "SUB"). 


\section{METHODS}

\section{Data Availability.}

All the results produced in this manuscript can be reproduced bit wise. The scripts used for creating figures and statistics are available through the following public Github repository:

https://github.com/fmassonn/paper-arctic-processes

Specifically, the two functions evaluating the IFE and OWFE will be incorporated in the Earth System Evaluation tool (ESMValTool, http://esmvaltool.org) for wider use by the climate community.

The data used in the scripts above can be retrieved from the following archive:

\section{https://doi.pangaea.de/10.1594/PANGAEA.889757}

Instructions on how to use this data and how to run the scripts can be found in the README.md file coming with the Github project above.

Domain of study for investigation of sea-ice thermodynamics. The goal of the present study is to investigate how vertical thermodynamic processes affect the Arctic sea-ice volume variability. The spatial domain must therefore be chosen appropriately in order to minimise the effect of sea-ice dynamics on the results. A recent study ${ }^{25}$ has shown that thickness variability at the local scale is largely dynamically driven. Conducting analyses at the modelgrid-cell level is therefore futile to measure thermodynamic processes. In contrast, a global domain (such as the whole Arctic) is not desirable either, as sea-ice volume and area would be impacted by horizontal oceanic processes which are not in the scope of our analyses. We chose the oceanic cap north of $80^{\circ} \mathrm{N}$ as reference domain for five reasons: (1) the domain is large enough to smooth out the effect of sea-ice dynamics on the area and thickness budgets, (2) it is located in the interior of the multiyear ice zone during the historical period (18612004) and therefore relatively sheltered from heat advected by the ocean from the south, (3) the domain retains sea ice (even in summer) in most CMIP5 models until at least the midcentury, while sea ice disappears seasonally elsewhere, (4) the domain is relatively well sampled in terms of observations of sea-ice thickness (ICESat campaign ${ }^{10}$ ), and (5) sensitivity tests conducted a posteriori with a 1-D thermodynamic sea-ice-ocean model (Fig. 2b, d) reveal a remarkable similarity in the efficiency of processes as a function of the mean state. This is of course not sufficient to claim that the choice of the domain is appropriate, but indicates that the first-order thermodynamics of sea-ice models can be investigated in that domain with reasonable confidence.

\section{CMIP5 simulations.}

Climate models. We analysed results from 44 GCMs participating to the Coupled Model Intercomparison Project, phase 5 (CMIP5) $)^{34}$, a suite of state-of-the-art climate models used as scientific support for, e.g., the last International Panel on Climate Change report (IPCC AR5) ${ }^{1}$. The number of 44 models corresponds to all models for which monthly mean outputs 
of sea-ice volume per unit grid-cell area (variable "sit") and sea-ice concentration (variable "sic") were available over the historical period (1861-2004). Each model provides from one to ten runs ('members') that aim at sampling the intrinsic internal variability of the climate system. We ran the diagnostics of the study for each member separately, but also presented for convenience the ensemble mean of those diagnostics for each model. The statistics reported, such as correlations, were always evaluated on the ensemble mean of diagnostics.

Sea-ice component in the models. Up to a few exceptions, nearly all climate models participating to CMIP5 have a similar sea-ice dynamical component, based on the so-called viscous-plastic rheology. The thermodynamic component of the models is more dependent on the model, with some models explicitly simulating the subgrid-scale ice-thickness distribution (ITD) and resolving heat conduction using multiple layers of ice and snow, while others assume that sea ice can be represented as a slab with no thermal inertia. A clustering of the 44 CMIP5 models used in this study was done based on the documentation found in the literature about the sea-ice components of those 44 models. Four groups were defined based on the complexity of their sea-ice component: (1) 'very simple' models, i.e. those without any representation (explicit or implicit) of the subgrid-scale ITD (2) 'simple' models, i.e. those with an implicit (virtual) ITD, that is, in which conductive heat fluxes are corrected for the unresolved nonlinear effects of the subgrid-scale ITD on vertical heat conduction fluxes, but with no assumed heat capacity for sea ice (the so-called "0-layer" thermodynamics) (3) 'intermediate' models, i.e. those with either an explicit ITD but following the 0-layer formalism, or with a virtual ITD but multiple layers of ice and snow, and (4) 'complex' models, i.e. those with an ITD and resolved multiple ice and snow layers. The correspondence between the model name and model complexity is given in Extended Data Table 1.

CESM-LE simulations. Due to the limited number of members available from CMIP5 models (maximum 10), we ran additional analyses with the Community Earth System Model Large Ensemble (CESM-LE) ${ }^{17}$ data set. This ensemble consists of $n=35$ members integrated from 1920 to 2100 under historical (1920-2005) and Representative Concentration Pathway ${ }^{32}$ (RCP) 8.5 (2006-2100) forcings. Similarly to CMIP5 models, the diagnostics were computed on monthly mean outputs of sea-ice thickness and concentration, on the native grid of the model. An overview of the ability of the CESM-LE to replicate observations is available in Extended Data Fig. 3 (to be compared with Fig. 1a of the main manuscript).

Observational and reanalysis data. Daily values of Arctic sea-ice extent (Fig. 1a) are retrieved from the National Snow and Ice Data Center (NSIDC) sea-ice index ${ }^{31}$. Observed sea-ice concentrations used for the evaluation of the Ice Formation Efficiency (IFE) and Open Water Formation Efficiency (OWFE) (Fig. 2c) are retrieved from the Ocean and Sea Ice Satellite Application Facility (OSI SAF) archive ${ }^{33}$. Observed sea-ice thicknesses from the ICESat satellite campaign ${ }^{10}$ are used for the evaluation of the two diagnostics (Fig. 2a-c). Caution must be placed in the interpretation of the two diagnostics derived from observations, as the reference period used to compute them is short (2003-2008) and the products themselves are uncertain, particularly for sea-ice thickness. However, these products give a first indication on the observed diagnostics and the resulting model biases. A sea-ice reanalysis (PIOMAS) ${ }^{22}$ was also analysed. It consists of a 1979-2015 integration of an 
ocean-sea-ice model nudged towards observed sea-ice concentrations and sea-surface temperatures. Although being first and foremost a product derived from model outputs, this reanalysis shows reasonable agreement with independent data ${ }^{22}$.

1-D sea-ice-ocean model. A one-dimensional thermodynamic sea-ice-ocean-mixed-layer model has been implemented to interpret physically the results obtained by GCMs. The code of that toy model is available as Supplementary Information (see 'Long-term availability and reproducibility of the results' hereunder). The interpretation of results obtained from this model should be made with caution, since this model lacks a number of processes and does not display spatial dimensions. The physics of the model is a simplified and one-dimensional version of the thermodynamic component of the Louvain-la-Neuve sea ice model, LIM $2^{35}$. Unlike LIM2, the toy model does not account for the thermal inertia of the ice, nor simulates ice dynamics nor snow processes.

Model. The model has four state variables: sea-ice volume per grid cell area, sea-ice concentration, sea-ice-surface temperature and ocean-mixed-layer temperature. No snow is present at the top of sea ice. At each time step, an energy budget is computed at the open ocean surface, and the heat imbalance is used to warm or cool a constant $30 \mathrm{~m}$ deep oceanic mixed layer. We recognise the limitations behind this assumption, as in reality mixed-layer depth exhibits seasonal variations ${ }^{36}$. If the updated oceanic mixed-layer temperature drops below the seawater freezing point $\left(-1.8^{\circ} \mathrm{C}\right)$, the equivalent energy is used to grow pure sea ice (0 PSU) in open water (volumetric latent heat of fusion: $300.33 \times 10^{6} \mathrm{~J} / \mathrm{m}^{3}$ ), with an initial thickness of $10 \mathrm{~cm}$. This newly formed ice is accreted to the existing ice from the previous time step. Then, an energy budget is computed at the top and bottom sea-ice surfaces to determine how surface and basal processes modify sea-ice thickness and concentration. The heat conductive flux through sea ice is derived from Fourier's law assuming a constant sea-ice thermal conductivity $(2.0344 \mathrm{~W} / \mathrm{mK})$ and constant bottom ice temperature $\left(-1.8^{\circ} \mathrm{C}\right)$. The conductive heat flux is boosted to account for the subgrid-scale variations in sea-ice thickness, assuming that it is uniformly distributed between $0 \mathrm{~m}$ and twice the mean thickness ${ }^{37}$. If the net energy balance at the sea-ice top surface is positive, sea-ice thickness is reduced uniformly assuming again that it is uniformly distributed between 0 and twice the mean value; this results in a decrease in sea-ice concentration. An energy budget is finally computed at the base of the ice. Here, a parameterised ocean-ice turbulent heat flux ${ }^{37}$ is used assuming constant sea-ice velocity $(1 \mathrm{~cm} / \mathrm{s})$, seawater density $\left(1024.458 \mathrm{~kg} / \mathrm{m}^{3}\right)$ and drag coefficient (0.005). The energy imbalance is used to grow or melt ice at the base of the existing ice floe.

Forcing. The atmospheric forcing used to drive the ice-ocean model follows the formulation of Notz, $2005^{38}$ based on the tabulated data of Maykut and Untersteiner, $1971^{39}$ and Perovich et al., $1999^{40}$. Incoming heat fluxes consist of a short-wave component and a 'non-solar' component. Sea-ice albedo varies throughout the year and is based on observational data. The incoming fluxes are perturbed to emulate the interannual evolving nature of the atmosphere.

Reference experiment. In the standard case, the model is initialized from a 1.0-m-thick sea-ice cover occupying $50 \%$ of the grid cell. Sea-ice-surface temperature is set to $-10.0{ }^{\circ} \mathrm{C}$ and the oceanic mixed-layer temperature is set to $-1.8^{\circ} \mathrm{C}$. The time step is one day. Under these 
conditions, the model reaches its equilibrium after $\sim 15$ years (Extended Data Fig. 4). The equilibrium annual mean ice thickness $(\sim 3.5 \mathrm{~m})$ corresponds, when integrated over the domain north of $80^{\circ} \mathrm{N}$ (surface: $3.87 \times 10^{6} \mathrm{~km}^{2}$ ), to the volume of $\sim 13.6 \times 10^{3} \mathrm{~km}^{3}$ marked by the black dot in Fig. $2 b-d$.

Sensitivity experiments. To produce the sensitivity experiments presented in Fig. 2b,d, we integrated the model under various changes in parameters and forcings for 100 years and conducted the analyses on the last 50 years of the simulations. We first incremented the seaice thermal conductivity by $10,20,30,40$ and $50 \%$, and then decreased it by the same amounts (blue dots in Fig. 2b,d). Then we incremented the annual mean sea-ice albedo by 1 , 2, 3, 4 and 5\%, and decreased it by the same amounts (we kept the ice thermal conductivity at its reference value). These are the green dots in Fig. 2b,d. Finally, we increased the annual mean value of the non-solar forcing by 1, 2, 3, 4 and 5\%, and decreased it by the same amounts (we kept both the ice thermal conductivity and the annual mean sea-ice albedo at their reference values). These are the red dots in Fig. 2b,d.

\section{The IFE and OWFE diagnostics.}

The evaluation of growth and melt processes require as input the time series of Arctic sea-ice volume north of $80^{\circ} \mathrm{N}$ (for IFE) and sea-ice volume and area north of $80^{\circ} \mathrm{N}$ (for OWFE). The original time series of volume and area from all 44 CMIP5 models are available in Extended Data Figs. 5 and 6.

Ice-formation efficiency (IFE). The evaluation of the IFE is graphically illustrated in Extended Data Fig. 7 (a,b). First, the time series of the Arctic sea-ice volume north of $80^{\circ} \mathrm{N}$ (see 'Domain for investigation of sea-ice thermodynamics' above) is computed. Then, for each calendar year of the time series but the last one, (1) the annual minimum sea-ice volume is recorded for that year $\left(V_{\min }\right)$ and (2) the annual maximum of the next year is recorded $\left(V_{\max }\right)$. The ice volume created $\left(\Delta V=V_{\max }-V_{\min }\right)$ is then computed. Finally, a linear regression is conducted between $V_{\min }$ ( $x$, predictor) and $\Delta V$ (y, predictand) over all years. The IFE is defined as the slope of the regression line between $\Delta V$ and $V_{\min }$. By default, both $\Delta V$ and $V_{\text {min }}$ are linearly detrended prior to the regression in order to avoid spurious relationships between those variables due to possible secular trends. This detrending does not affect the conclusions of the manuscript (Extended Data Fig. 8a).

The IFE is a dimensionless number and can be interpreted as the efficiency of a model to recover a summer anomaly of sea-ice volume either completely (IFE $=-1.0$ ) or not at all (IFE $=0.0$ ).

Extended Data Fig. 9 illustrates the methodology for all 44 CMIP5 models.

Open-water-formation Efficiency (OWFE). The diagnostic derives from from Holland et al., $2006^{8}$. The evaluation of the OWFE is graphically illustrated in Extended Data Fig. 7 (c,d). First, the time series of the Arctic sea-ice volume and area north of $80^{\circ} \mathrm{N}$ (see 'Domain for investigation of sea-ice thermodynamics' above) are computed. Then, for each calendar year of the time series, the months of annual maximum and minimum sea-ice volumes are recorded 
( $t_{\min }$ and $t_{\max }$, respectively). The volume loss for that year $\Delta V=V\left(t_{\min }\right)-V\left(t_{\max }\right)$ is estimated. The area loss for that year $\Delta A=A\left(t_{\min }\right)-A\left(t_{\max }\right)$ is computed. Note that the area difference is not taken between the minimum and maximum of area time series, which do not necessarily coincide with the timings of volume extrema. Finally, a linear regression is conducted between $\Delta V$ ( $x$, predictor) and $\Delta A$ (y, predictand) over all years. The OWFE is defined as the slope of the regression line between $\Delta A$ and $\Delta V$. By default, both $\Delta A$ and $\Delta V$ are linearly detrended prior to the regression to avoid spurious relationships between those variables due to secular trends. This detrending does not affect the conclusions of the manuscript (Extended Data Fig. 8b).

The OWFE is a number with units $\mathrm{m}^{-1}$ and measures the efficiency at which a model forms open water (or reduces sea-ice area) given a unit reduction in sea-ice thickness ${ }^{8}$.

Extended Data Fig. 10 illustrates the methodology for all 44 CMIP5 models.

Physical meaning. It is important to recognise that neither OWFE nor IFE are strict measures of feedback per se. However, since both melt and growth processes are central elements in the negative and positive feedback loops described above, the two diagnostics allow appreciating the first-order role played by sea ice in these feedbacks.

Uncertainty. Both IFE and OWFE are defined as regression coefficients. The standard deviation of the estimated coefficients is taken as the measure of uncertainty on the two diagnostics (e.g., for observations and the reanalysis in Fig. 2). The uncertainty in annual mean sea-ice volume is defined as the standard deviation of annual mean sea-ice volume time series (e.g., Figs. 2 and 3).

No sensitivity to reference period. The analyses with CMIP5 models are conducted over the reference period 1955-2004, which corresponds to the last 50 years of the historical period defined by the CMIP5 protocol ${ }^{34}$. The robustness of the findings was tested using different periods. Results were found to be insensitive to this choice (Extended Data Fig. 11). Results were also found to be robust with respect to the separation in time: computation of OWFE and IFE on an earlier period than the Arctic sea-ice variability indices yields similar results (Extended Data Fig. 12).

\section{Can we reduce uncertainties in projected ice-volume trends?}

Bitz and Roe (2004) ${ }^{9}$ first identified a robust relationship between the simulated Arctic annual mean sea-ice volume and the projected volume loss. In line with their conclusions and with the physical arguments given in our manuscript, we also reproduce this result (Extended Data Fig. 13). From this relationship, it would appear natural to subset the CMIP5 ensemble based on their ability to simulate the observed annual mean sea-ice volume in our domain of study (i.e., the $x$-axis of Extended Data Fig. 15). However, there are at least four obstacles that make the application of this constraint difficult: (1) there is considerable uncertainty in the raw retrievals in observations of ice freeboard and draft due to instrumental error, (2) there is considerable uncertainty in the deduced sea-ice thickness due to assumptions (e.g., hydrostatic equilibrium, climatological snow load) and the parameters used to convert the raw 
measurements to sea-ice thickness (snow and ice density are taken as constants) $)^{30}$, (3) the period for which large-scale estimates of sea-ice volume are available is short ( 15 years) and interannual variability is large, meaning that time averages are subject to large sampling errors, and (4) sea-ice thickness uncertainties are particularly large (or no sea-ice thickness estimates are available) in summer. Given all these sources of uncertainty, it appears clearly that reliably estimating the true annual mean sea-ice volume from observations is impossible nowadays, and hence applying a reliable constraint based on the annual mean sea ice volume is not feasible.

As an alternative, we follow a much less constrained approach. We discard simulations that have a monthly mean sea-ice volume north of $80^{\circ} \mathrm{N}$ systematically higher or lower than three standard observational references: IceSat, CryoSat2 and the ITRP datasets ${ }^{10,41,42}$ over the period of observational data availability (2000-2017, Extended Data Fig. 14). In other words, we disregard simulations for which the sea-ice volume north of $80^{\circ} \mathrm{N}$ for each month of each year is always outside the observational range. Applying this constraint on the CMIP5 ensemble (RCP8.5, 2005-2100), we discard 14 simulations out of 72 available. The ensemble mean of 2020-2050 projected ice-volume loss hardly changes after the application of this constraint (from -6.85 to $-6.80 \times 10^{3} \mathrm{~km}^{3}$ ) and the spread around these estimates is only reduced by about $17 \%$ (from 3.08 to $2.56 \times 10^{3} \mathrm{~km}^{3}$ ) (Fig. 4).

\section{METHODS-ONLY REFERENCES}

34. Taylor, K. E., Stouffer, R. J., Meehl, G. A. An overview of CMIP5 and the experiment design. Bull. Am. Meteorol. Soc. 93 485-498 (2012)

35. Fichefet, T. \& Morales Maqueda, M. M. Sensitivity of a global sea ice model to the treatment of ice thermodynamics and dynamics. J. Geophys. Res. 102 C6 1260912646 (1997)

36. Tsamados, M., Feltham, D., Petty, A., Schroeder, D. \& Flocco, D. Processes controlling surface, bottom and lateral melt of Arctic sea ice in a state of the art sea ice model. Phil. Trans. Roy. Soc. A 373, 2052 (2015)

37. Goosse, H. \& Fichefet, T. Importance of ice-ocean interactions for the global ocean circulation: A model study. J. Geophys. Res. 104 23337-23335 (1999)

38. Notz, D. Thermodynamic and fluid-dynamical processes in sea ice. Ph.D. thesis, University of Cambridge (2005)

39. Maykut, G. A. and Untersteiner, N. Some results from a time-dependent, thermodynamic model of sea ice. J. Geophys. Res., 76 1550-1575 (1971)

40. Perovich, D. K., Grenfell T. C., Light B., Richter-Menge, J. A., Sturm M., Tucker III, W. V., Eicken, H., Maykut, G. A. and Elder, B. SHEBA: Snow and Ice Studies CDROM. Technical report, Cold Regions Research and Engineering Laboratory (1999) 
41. Hendricks, S., Ricker, R. and Helm, V. AWI CryoSat-2 Sea Ice Thickness Data Product (v1.2),

User

Guide. http://www.meereisportal.de/fileadmin/user_upload/www.meereisportal.de/MeereisBe obachtung/Beobachtungsergebnisse_aus_Satellitenmessungen/CryoSat2_Meereisprodukt/AWI_cryosat2_user_guide_v1.2_july2016.pdf (2016)

42. Lindsay, R. and Schweiger, A. Arctic sea ice thicknes loss determined using subsurface, aircraft, and satellite observations. Cryosphere 9, 269-283 (2015) 


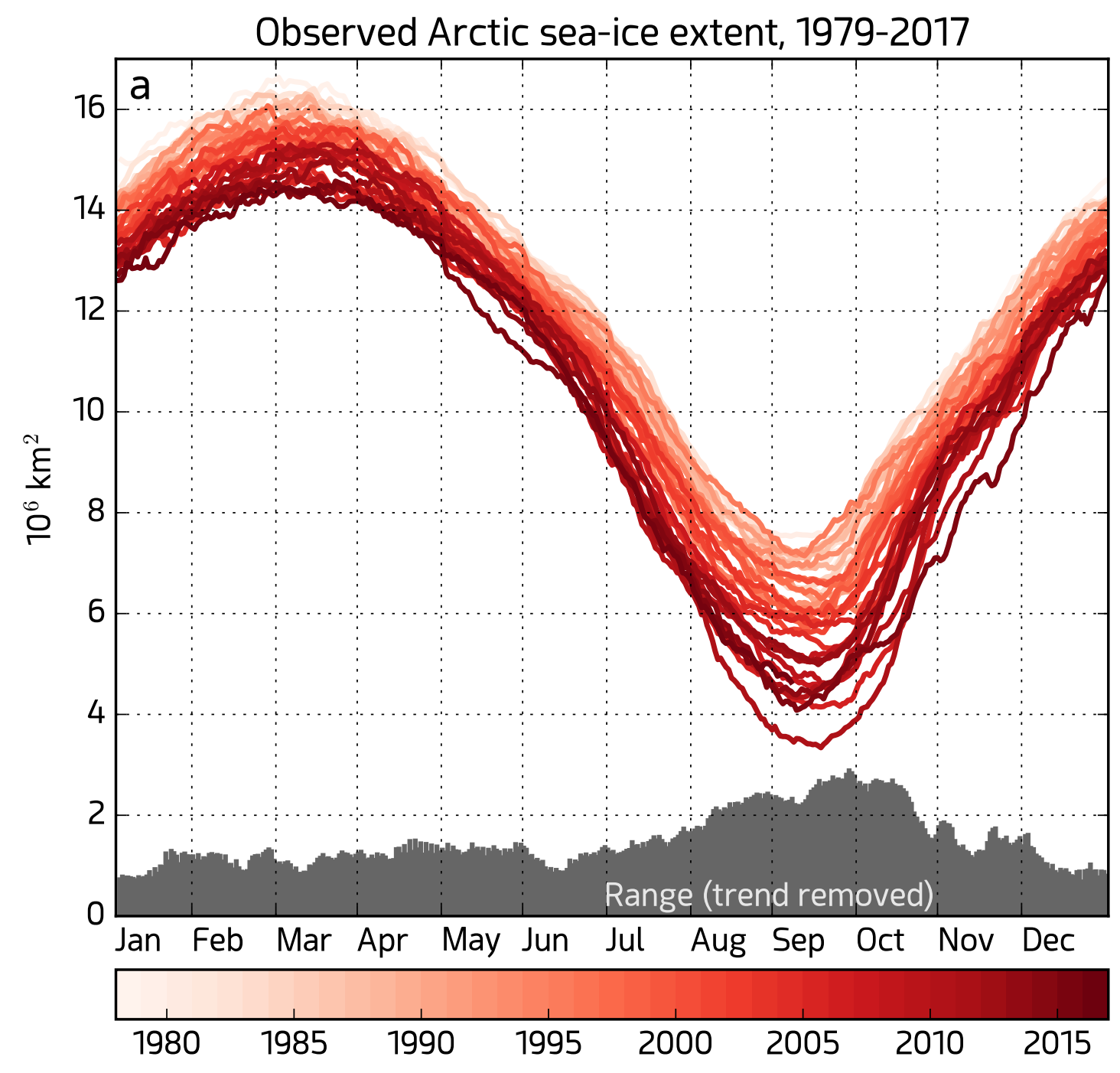

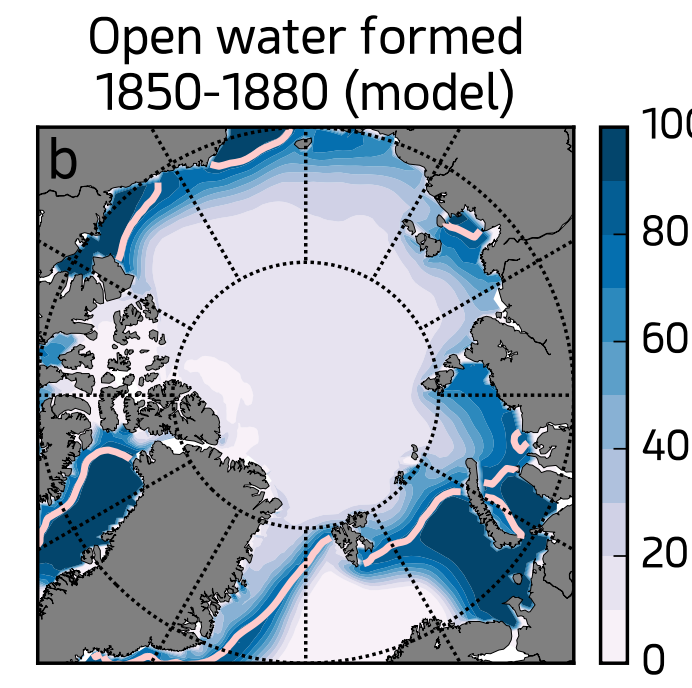

Open water formed

2020-2050 (model)

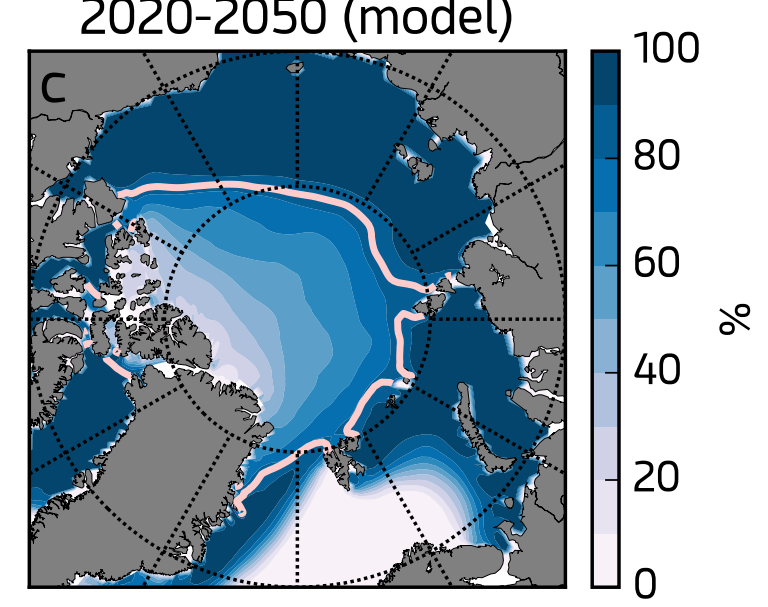

Ice thickness seasonal change 1850-1880 (model)

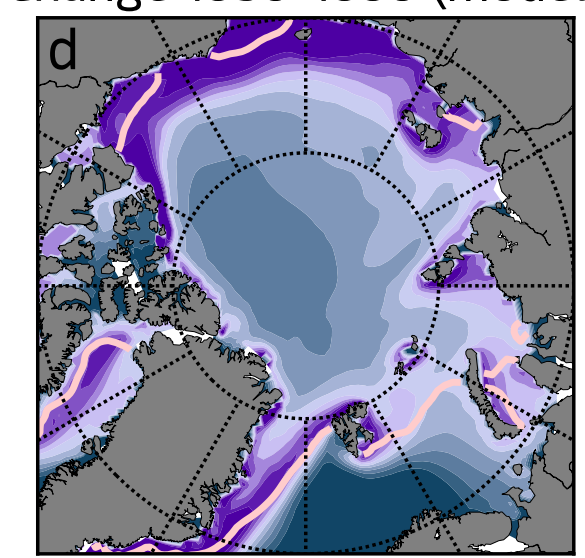

Ice thickness seasonal change 2020-2050 (model)

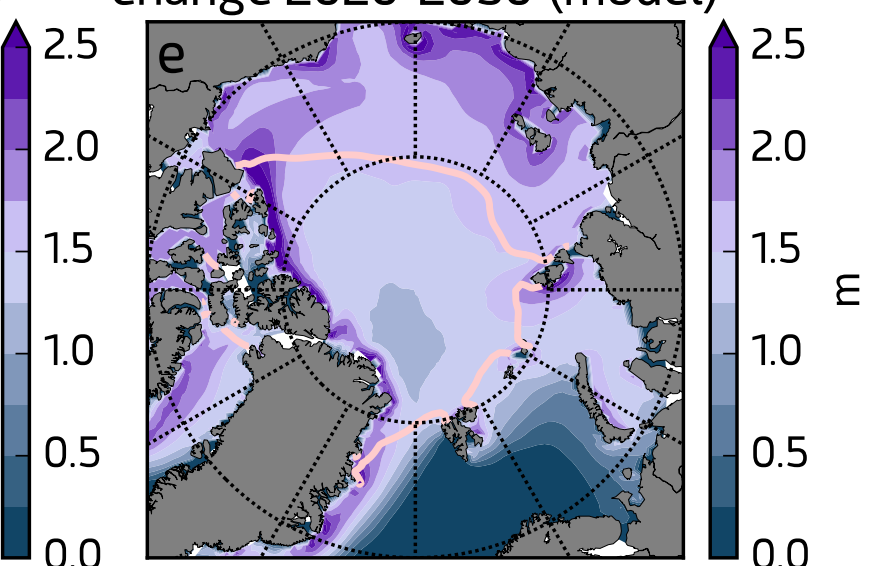



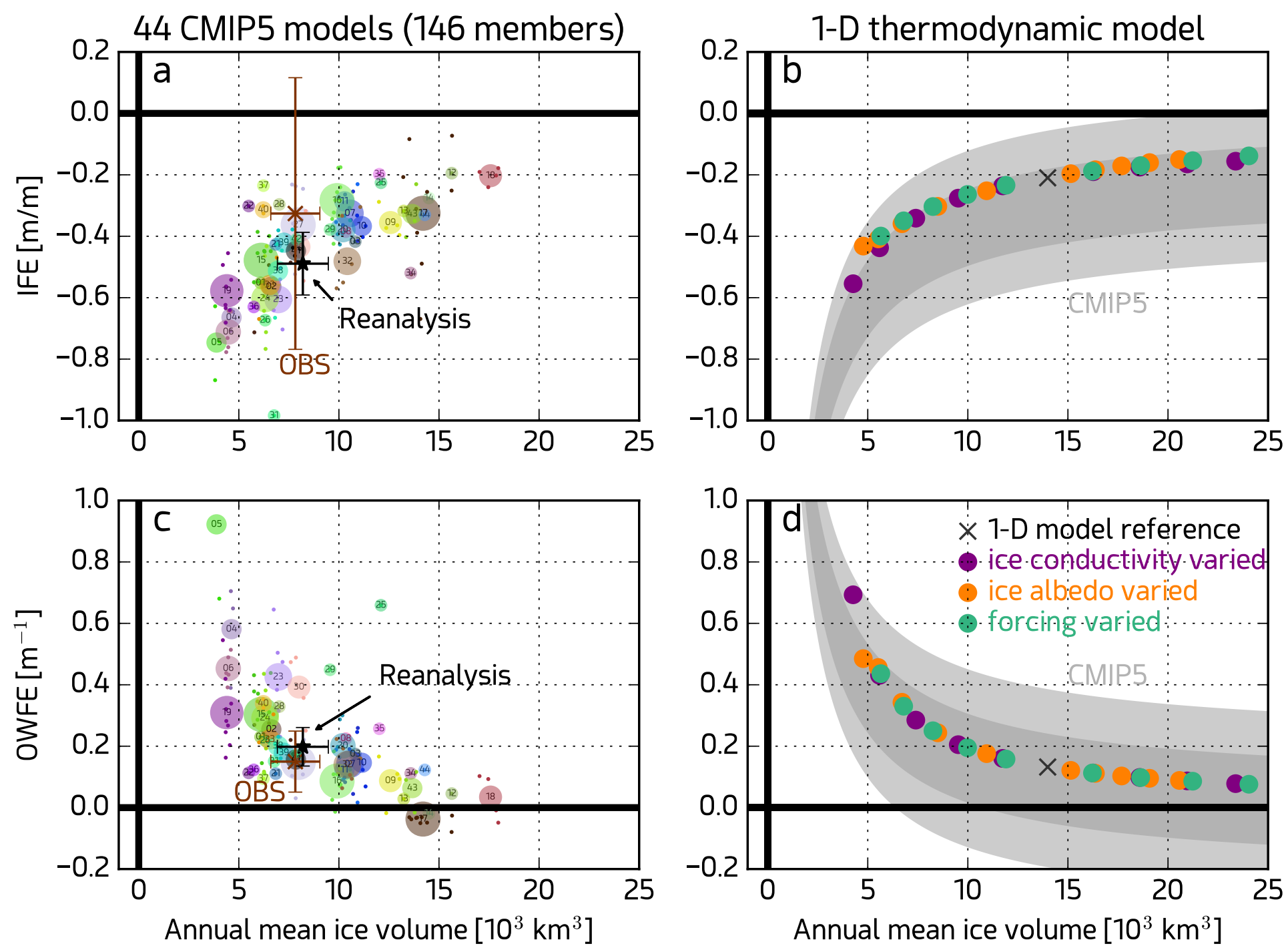
CESM large ensemble (35 members) historical + RCP8.5 forcings
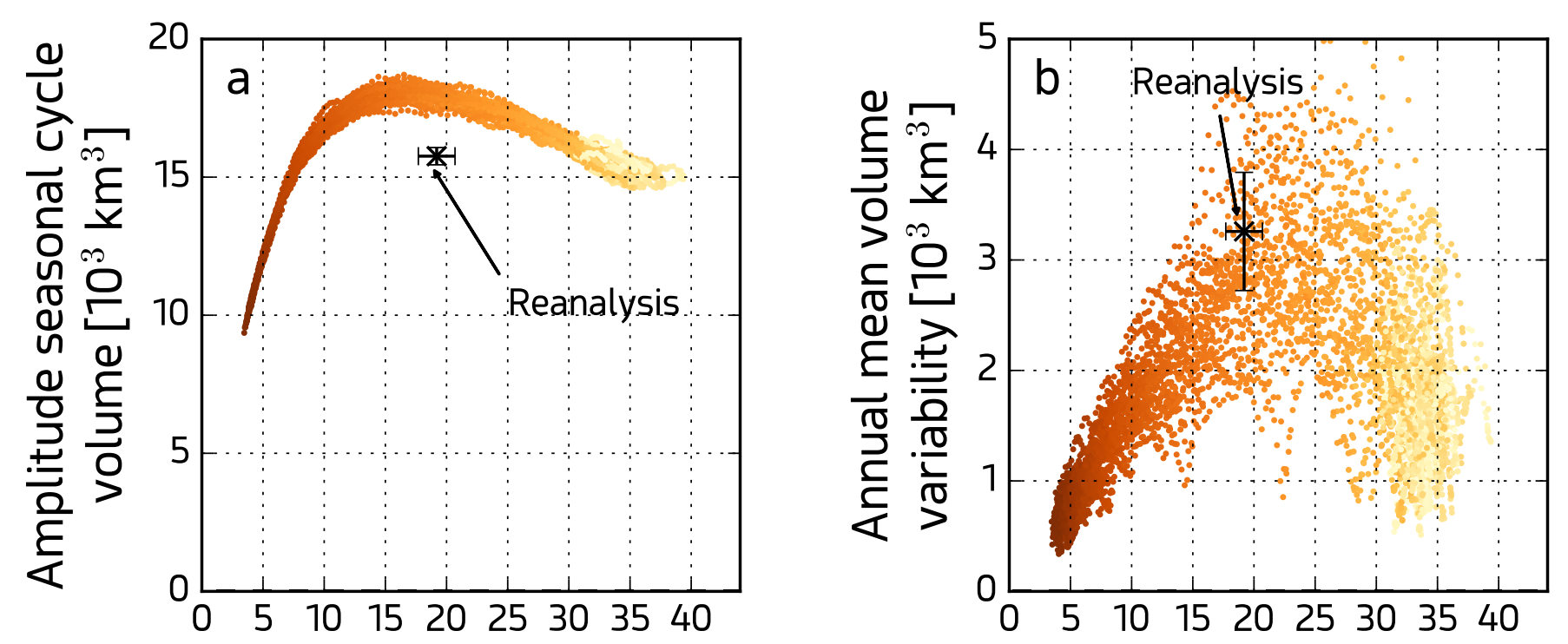

2080-2100

2070-2090

2060-2080

2050-2070

2040-2060

2030-2050

2020-2040

2010-2030

2000-2020
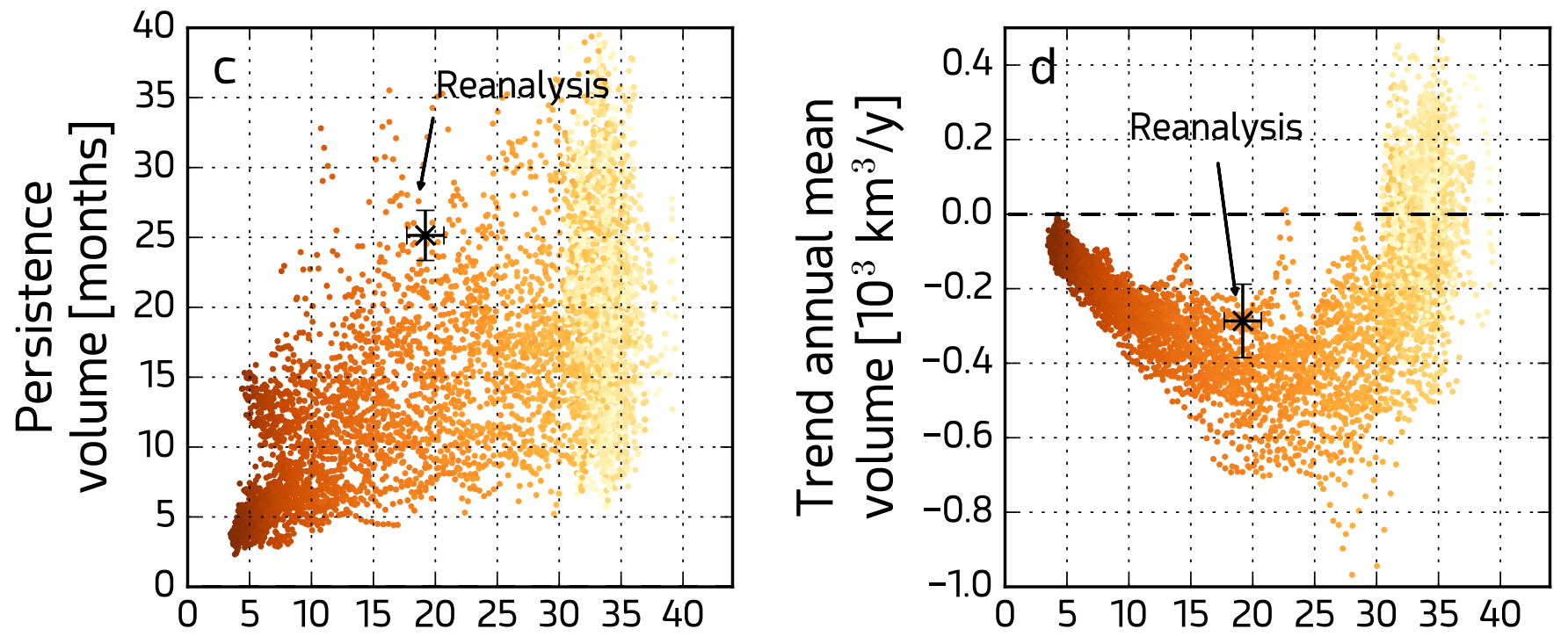

1990-2010

$1980-2000$

1970-1990

1960-1980

1950-1970

1940-1960

1930-1950

1920-1940

Annual mean sea-ice volume $\left[10^{3} \mathrm{~km}^{3}\right]$ 


\section{CMIP5 simulations}

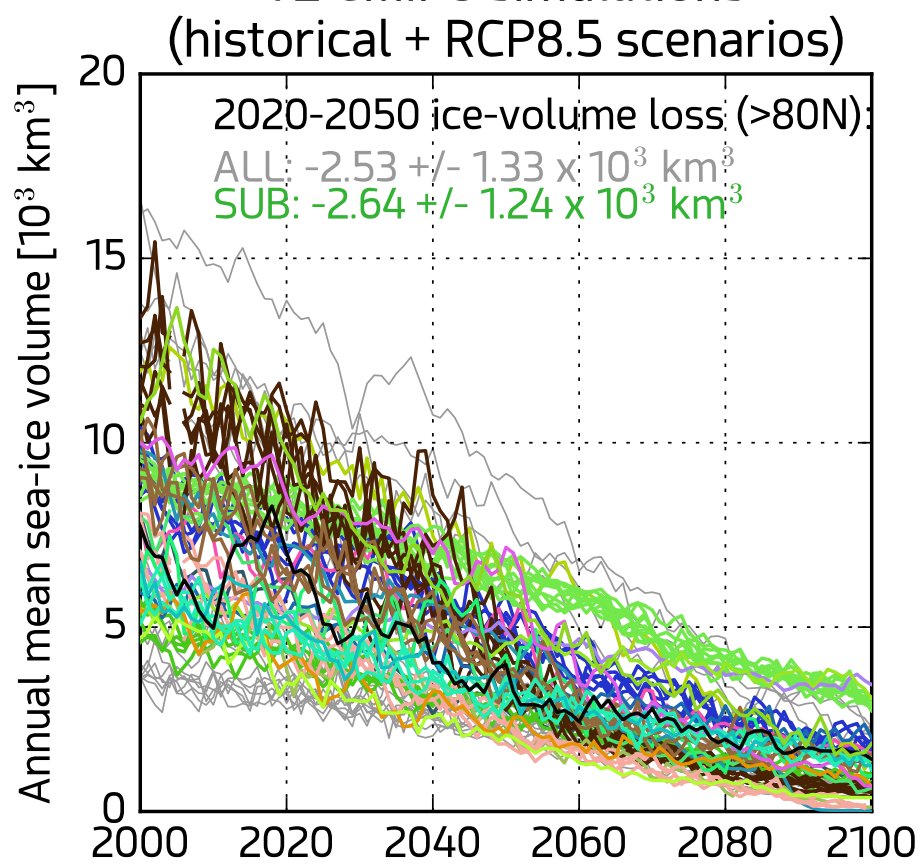

